\title{
REVIVING ISLAMIC VALUES IN CONTEMPORARY ARAB ARCHITECTURE ICASE STUDY
}

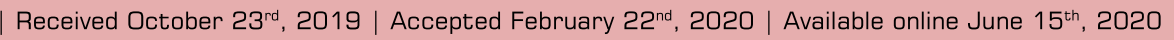

| DOI http://dx.doi. org/10.18860/iia.v6i1.7848 |

\section{Heba Badi Alqub}

Department of Geography, Planning and Environmental studies, Concordia University, Montreal, Canada

"On leave from Applied Science private University (ASU) Hebabadiud@hotmail.com

Robert Mellin

School of Architecture, McGill University,

Montreal, Canada

robert.mellin@mcgill.ca

\begin{abstract}
Contemporary architecture in the Arab-Islamic World is facing the challenge of finding a distinctive character that combines both the heritage of the regional building traditions and the modern society lifestyle. Since few apparent attempts aim to articulate an identity for regional architecture, this research investigates the work of the Jordanian architect, Ayman Zuaiter. Their jobs attempt to integrate the cultural values and traditions with the contemporary Arab-Islamic architecture and seek to express and represent the spirit, values, and underlying principles of the regional heritage. This study aims to offer a deeper understanding of design as both method and production, contributing in turn to understanding regional and socioeconomic considerations behind forms. This study will be based on the analysis of one of Zuaiter's residential buildings, Al-Tabba'a House. The research method is mainly exploratory, which combines a review of the project primarily in terms of cultural context; responding to the site itself (understanding regional and socio-economic considerations behind forms); concepts and how techniques helped them appear the way they are; multiple personal interviews with the architect aiming to understand his design strategies to revive traditions; and the external influences that affect the design process. This study shows that Islamic Values could be delivered through each design feature in Ayman Zuaiter's work of contemporary Arab architecture.
\end{abstract}

\section{KEYWORDS:}

Architecture; Regionalism; Modernity; Tradition; Architectural Identity

\section{INTRODUCTION}

"Search for identity could give us a much greater sensitivity not only to our environment but to ourselves and to the society in which we live." [1]

Contemporary architecture in the Arab-Islamic World is facing the challenge of finding a distinctive character that combines the heritage of historical regional building traditions with the expression of modern society [2][3]. Since few apparent attempts aim to articulate an identity for regional architecture, the need for such a study appears strongly.

Architecture is the purest way of expressing and effectively reflecting the evolution of human civilization and culture [4]. It is also a source for an individual's perception of his environment and is considered to be an essential component of human knowledge. Regarding the Arab-Islamic world, the current attitudes toward architecture hardly seek to render an identity for contemporary architecture, through which they would be able to express their culture and traditions [5] [6]. To achieve this goal, one should employ rituals in modern designs in an attempt to harmonize the two domains. The root of this interest in identity and tradition regionally came as a consequence of changes on two primary levels; the dramatic change in the Arab-Islamic world -mainly by discovering oil in areas- that provoked different reactions in architecture toward this sudden change, and the shift in the global architectural culture.

Consequently, the Arab world was influenced by this shift. Like any other place, modern architecture failed to satisfy expectations, and the result was a lack of meaning and connection with the culture and traditions of the site. The pure abstraction of modern architecture that tried to accommodate a universal style faced a significant dissatisfaction regionally, which drove them back toward legend and identity [5].

Different strategies and methodologies have been adopted by Arab architects and thinkers to deal with the issue of modernity versus tradition [7][8]. Different reactions emerged from different architects toward this issue, depending on their perceptions, which complicated the situation even more [9][10]. Moreover, the architects who were interested in this issue are divided into two groups; the first group adopted the theoretical methodology in studying tradition and modernity with total ignorance to the practical side, while the other group had tangible practices with no academic background to form a foundation of their works. Hence, this created a 
considerable gap between theory and practice.

As a result, a positive response towards more sensitive approaches to this issue started to appear in the fifties through a few famous names, such as Rifa Chadirji and Hasan Fathy, who had a decisive role, but that was not enough. Nevertheless, a tangible shift happened in the late seventies and the early eighties when a new generation of Arab architects seriously attempted to form a relevant idiom and an architectural approach to articulate a cultural identity in the region [5].

Moving from the macro to the micro context, this study focuses on Jordan, an excellent example of a place where one could correctly notice the balance between local and global modern values. Different architects with diverse backgrounds have gathered at one place-Jordan-and contributed to the establishment of a particular context with unique attempts to re-connect again with the cultural values. However, only a few apparent efforts that aim to articulate an identity for regional architecture take place in the region. Thus, this research examines an example of one of the new generation Arab architects who take responsibility for establishing a secure connection between tradition and modernity in their practices and trying to revive traditions and cultural values in the contemporary architecture of the region. Zuaiter, as the selected architect for this study, clearly shows an interesting example of how proper incorporation between old and new could be made in contemporary architecture.

This research investigates the work of the Jordanian architect Ayman Zuaiter. Their jobs attempt to integrate the cultural values and traditions with the contemporary Arab-Islamic architecture, and seeks to express and represent the spirit, values, and underlying principles of the regional heritage. Zuaiter tried in his designs to sustain the culturally inherited values as a reaction to the massive external influences of foreign cultures on the local architecture. This study will be based on an analysis of one of Zuaiter's residential buildings: Al-Tabba'a residence (house).

The objectives of the research are twofold: 1-To help in deeply understanding design both as a method and production. 2-To contribute to understanding how Zuaiter's design strategies aim to connect architecture to its context, people, and heritage, revealing the Islamic values he applied in his architectural practices that help to revive Islamic values in the contemporary Arab architecture.

\section{RESEARCH RATIONALE (PURPOSE)}

Since the need for regional architectural identity in the Arab world is pressing, along with the lack of serious attempts in this regard, this paper investigates the work of the Jordanian architect Ayman Zuaiter whose work he claims is aiming to articulate a unique architectural identity. This study will be based on the analysis of one of Zuaiter's residential buildings: Al-Tabba'a residence

\section{RESEARCH QUESTION}

The research question of the study is as follows: How has Zuaiter integrated and translated the cultural values and traditions into his residential project: Tabba'a residence?

\section{THE RATIONABLE OF THE CASE STUDY SELECTION}

A residential building was chosen due to what is mentioned by Al-Abbassi [4] that a "house" is considered to be the first place in which human feelings and identity come from through their connection to the situation. It is the mirror that reflects a man's culture, traditions, and heritage that is stretched out from the society he belongs to. It is considered the most successful architectural example that honestly expresses the local identity and the human ambitions to build a place where he could settle for life. While talking about the house as an essential part of the architecture, Matrouk and Goussous say:

"The house is the most intimate place for man... Memory in this regard is part of the house-making and its internal sentiments. No one could imagine a house designing apart from the accumulated experience of the place which has formed our mental environment" [11].

\section{RESEARCH METHODOLOGY}

The methodology followed in this study is based on an exploratory and inductive approach. Exploratory approach, in other words, is based on the individual's experience moving through the house, exploring its different spaces as a lived experience. It is worth mentioning that the lived experience is an indispensable quality that should be paying attention to when considering Islamic architecture. Along with the visitor's journey through the house, other analytical techniques were used to explain the architectural practices, the design elements used, and the cultural meanings and values behind them. To mention these techniques (methods): building observations, physical environment analysis, Architectural drawings- which were reproduced by the author, architectural sketches of unique details, photographs, and multiple in-depth interviews with the architect. The strategy followed to do the study is to pick one residential project of the architect Ayman Zuaiter to be examined to show how this project reflects local architectural identity and effectively revive cultural values in modern practices.

The inductive approach was used in the conclusion section by the researcher, trying to put the results together, making the invisible visible. Through organizing the design elements and Islamic values associated with them, an initial guideline is provided on which more advanced ones could be built in the future, contributing in making design serve as both a method and production.

\section{THE CASE STUDY ANALYSIS :}

\section{The context}

The Tabba'a House is located in Abdoun, one of the most modern parts of Amman. The location itself stresses the fact that there is no contradiction 
between modernity and tradition, but an attractive integration could be created to combine them smoothly.

Also, this case shows a site that is located on a bit steep land, which is considered a challenge for the architect to deal with. Therefore, he tried to extract the beauty of the site without ignoring its hard nature (figure 1 and 2).

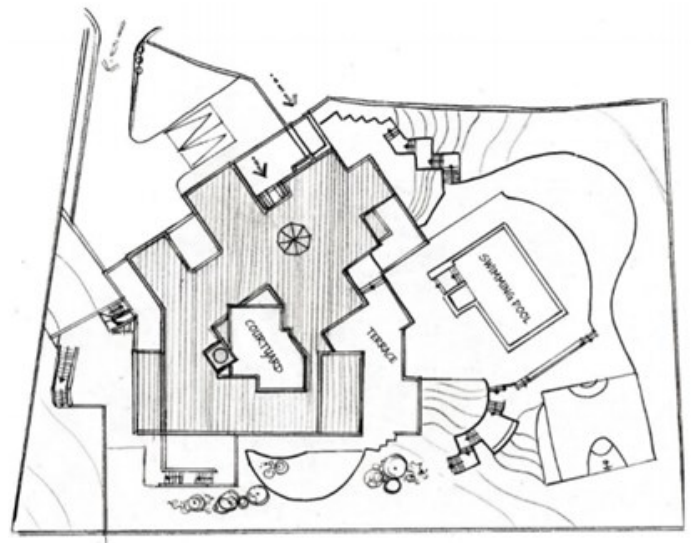

Figure 1. A sketch of the site plan of Tabba'a House [Source: reproduced by the author]

Design Concept of the main form of the floor plans

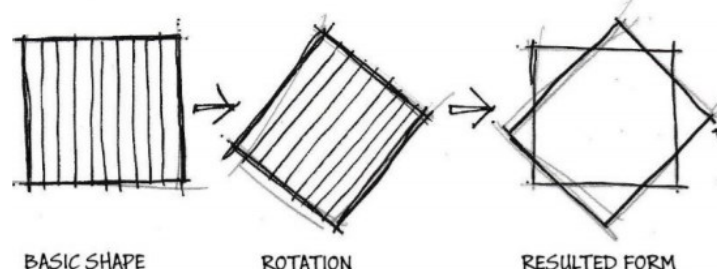

BASIC SHAPE

ROTATION

RESULTED FORM

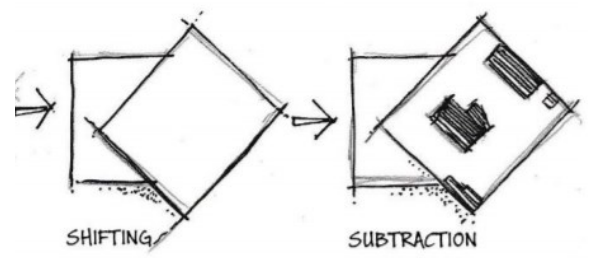

Figure 2. A sketch of the process of generating the final design form (design concept) [Source: the author]

Special Design Elements: Internal Courtyard

As mentioned previously, Tabba'a House is located on relatively high land, hence a bit steep. According to Zuaiter, this site was almost empty at the time of starting the work. It faces a beautiful view of the hills of Amman, where one could spend all day just relaxing and enjoying the particular scene. Therefore, the client strongly wanted to save a significant portion of the land from looking out on it, but Zuaiter had a futuristic vision of the site. He expected the view to be soon ruined by the real estate companies that would fill the area with high rise buildings blocking that view in the coming years, making the site lose its glory. Unfortu- nately, that is precisely what happened. Thus, Zuaiter had taken the right decision when he suggested to the client to have his view, his own public space that would be open to the sky and would not be blocked or affected by external changes. That is, the internal courtyard, and what makes it unique in this case is that it is internal (from all sides). It is noteworthy in this regard to mention that the courtyard is considered to be a significant element in the traditional Arab-Islamic house, which has been used in most of Zuiater's work, see figure.3.

In the Arab cosmology, the four walls of the courtyard indicate the four columns carrying the dome of the sky, and the yard symbolizes their piece of sky. However, they preferred to have the main entrance open into this clean and holy space, which is on the scale of the house, rather than into the public street, which is on the size of the city [12] [13].

On another note, the internal courtyard serves as a mediating zone that links the house's private sections to the public ones smoothly. By doing so, the value of privacy is achieved. See figure. 4 and 5 .

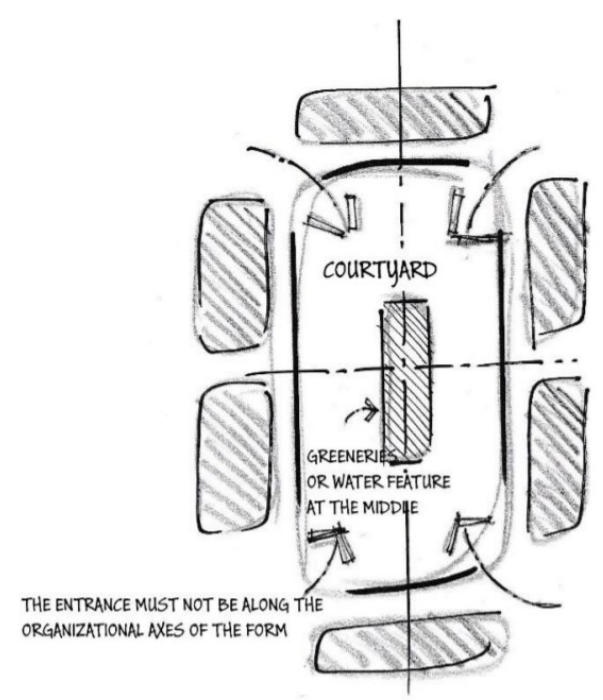

Figure 3. A sketch of the internal courtyard applied in Zuaiter's projects- the possible entrances mustn't be along the organizational axes of the form [Source: the author]

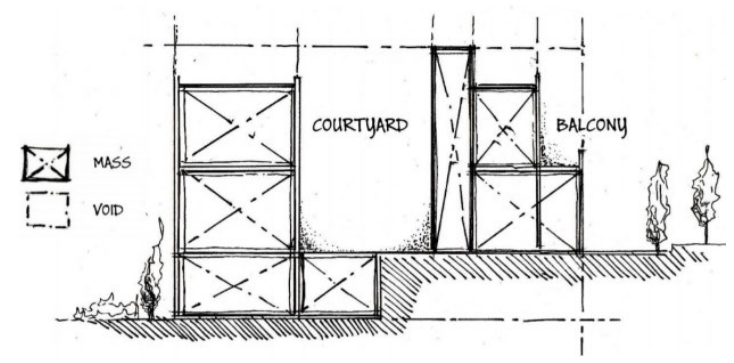

Figure 4. The analytic section displays the geometry (mass and void) of the form- Tabba'a House [Source: the author] 


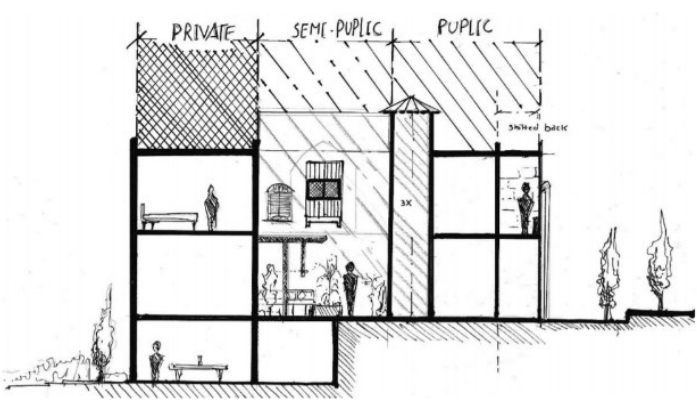

Figure 5. The analytic section shows Tabba'a house zoning- the courtyard as a link between private and public parts [Source: the author]

\section{Richness is indoor}

Once a visitor reaches the house, they are met by a humble wooden door-a single small entrance-, and that refers to a valuable traditional principle that "The richness is indoors." It emphasizes the value of having social equity and respect for neighbors. With no visible richness to the public, all houses will appear similar from the outside. Hence the poor could live just right beside the rich without anyone distinguishing social differences between them. By doing so, the general look of the neighborhood will be unified, and the social ties will be strengthened among all the neighborhood residents.

In this regard, one example that Zuaiter noticed during his visit to Morocco is one in which two different courts that belong to two different houses have been located just right beside each other yet show completely different social levels with no exposed difference to the public as shown in Figure.6.
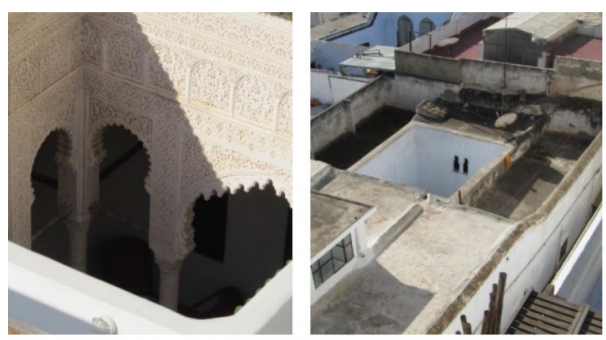

Figure 6. A well-detailed rich court (left) vs. a simple court (right). Both courts are located just right beside each other [Source: Ayman Zuaiter]

\section{Movement Line Vs. Organizational Axes}

Tabba'a House exhibits this value. The entrance is a modest wooden door just right beside a big tree-that will be further described later-, this door is located to the side of the wall, not in the middle. There are hidden secrets for choosing this unusual location of the main entrance. First of all, by making it small in size, it makes it closer to the human scale, so it evokes feelings of comfort and being welcomed. Secondly, the side location of the door changes the general direction of movement, which often goes along the main organizational axes. Zuaiter was inspired by The Hambra Palace in Al-Andalus, which is also known as Muslim Spain, an occupied medieval Muslim territory and cultural domain in present-day Spain and Portugal. The region was under Muslim rule from 711 to 1492 . Using this principle keeps the residents' privacy preserved by not making the movement line axial or not along the organizational axes of the plan.

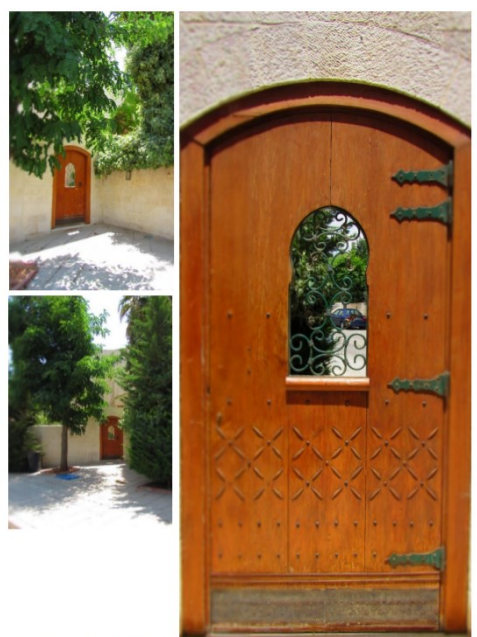

Figure.7. Making the main approach sideway with a humble wooden door as the main entrance [Source: the author]

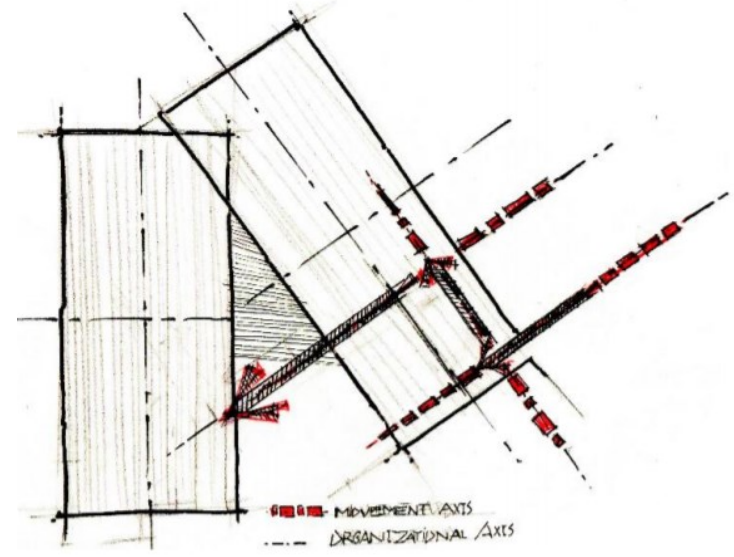

Figure 8. A sketch shows the movement line which is not along the organizational axes of the Tabba's house plan [Source: the author]

The main door opens to the entrance courtyard at the back. It is almost a small court surrounded by stone columns and a small garden all around the courtyard in order to define the space, see figure.5. At the center of the courtyard, there is an elegant fountain that reminds us of the Córdoba palace in Al-Andalus. Water features are highly recommended in Islamic Architecture, as water is considered the basis of all living beings (figure 7 and 8).

\section{The Iwan}

This entrance court leads to a huge Arch (Iwan), an Arab house element that is often a rectangular vaulted space, closed on three walls, and opened entirely on the forth side, see figure.6. It includes a heavy wooden door and a Mashrabiya above it-a wooden screen 
enclosed with carved wood that provides shade, sunlight, air, and privacy. It will be defined in more detail later. This Arch is nearly covered with climbing green Vines that constitute a capturing scene as if someone is looking at an exquisite portrait (figure 9 and 10).

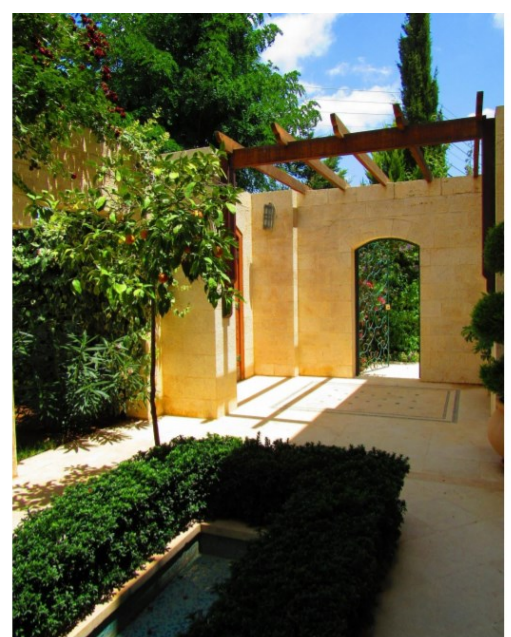

Figure 9. The entrance court [source: the author]

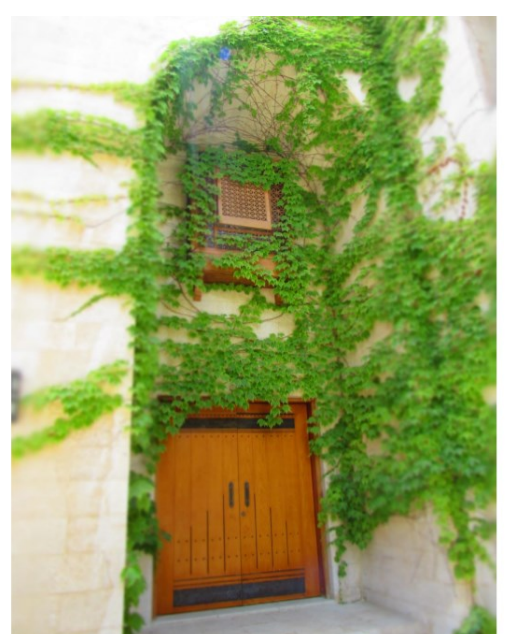

Figure 10. The house Iwan has a door and a Mashrabiya above [Source: the author]

The Majestic Hall and More

Behind the Iwan, there is a surprise: three delicate columns lined up next to a triple volume hall, which is the entrance hall or the reception. It is worth mentioning here that this is the system that has been followed by Zuaiter to show that one has reached the host or the lobby. This majestic hall combines several traditional elements such as Mashrabiya, a domed building, and local lanterns and colored glass windows at the top. Through the columns, one could reach either straight to the central court, the stairs to the right, or the guest and living area to the left. From this distribution point, one could notice that the house plan has a modern style, an open layout. The guest and the living areas overlook a wide terrace that looks out on a swimming pool and a well-designed garden outside. The nursery follows the Islamic garden model. The
Islamic garden is a symbolism of paradise and has two integral elements, namely that are, shade and water [14][15]. Since the concept of a garden in this part of the world means a cool place for relaxing and rest due to the hot arid climate, one must find a shaded sitting area and a water feature in such gardens. The most conspicuous features in Zuaiter's nursery are a water feature and a shaded, cool sitting place (figure 11).

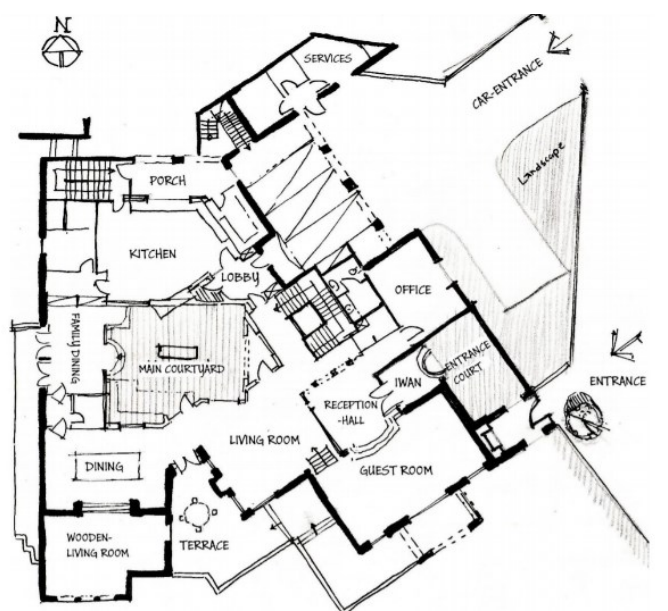

Figure 11. A sketch of Tabba'a House ground floor plan. [Source: Reproduced by the author]

\section{Horseshoe Arches}

While approaching the living room and passing through the classic wooden dining room, an ornamented wooden enclosure surrounds this fascinating space, where one could feel the magical eastern ambiance. The apparent influence of AlAndalus palaces could be easily recognized in the use of the three horseshoe arches just behind the sitting area, creating a charming contrast between the sunlight that penetrates the space and the deep dark color of this well-selected tekk wood (figure 12 and 13).

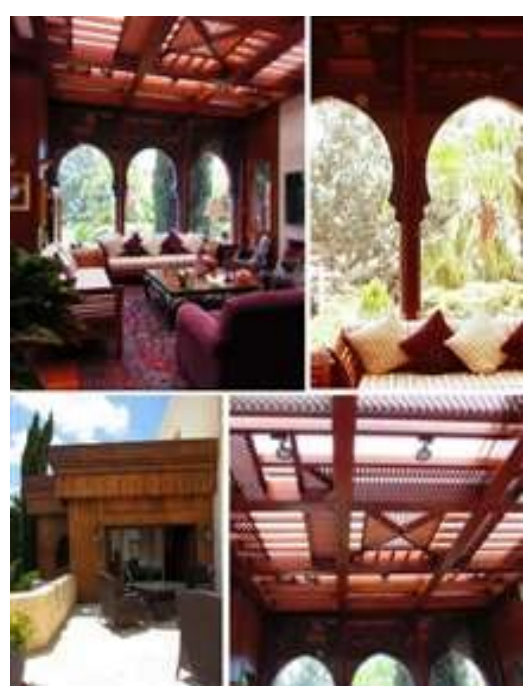

Figure 12. The wooden living area with its horseshoe arches from inside and outside.[ source: the author] 


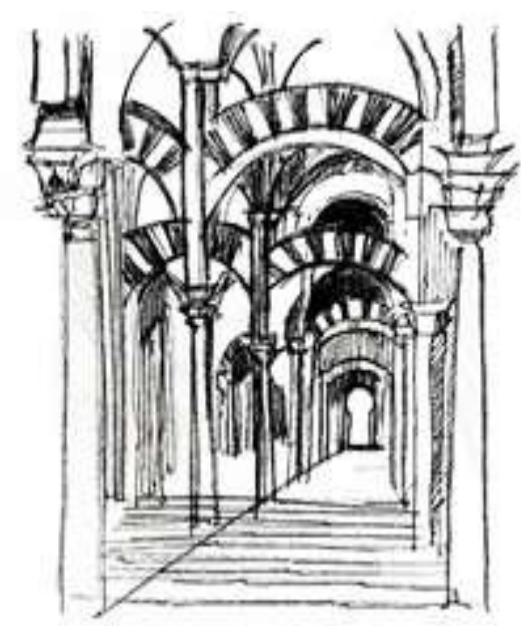

Figure 13. A sketch of Cordoba arches in Al-Andalus, showing its influence on Zuaiter's design. [Source: the author]

The Courtyard as the Design Reference

Going back to the three columns of the reception hall, if one decides to skip the stairs, a short corridor leads to another distribution point that leads to two routes; one leads to the central courtyard, and the other one to the kitchen, which also has multiple windows looking out at the central courtyard. Zuaiter describes this main courtyard as the heart of the house. It is a piece of paradise on earth. Interestingly, going back to history shows that traditionally, people used to design homes by first determining and developing the courtyard as the main element of the house. Then, based on that, they would arrange the other house spaces. In other words, they used to layout the courtyard and then filled on the different areas, which could be described as a charming architecture that must be read from the inside to the outside. The yard was considered as the house reference, which indicates its significance historically (figure 14).

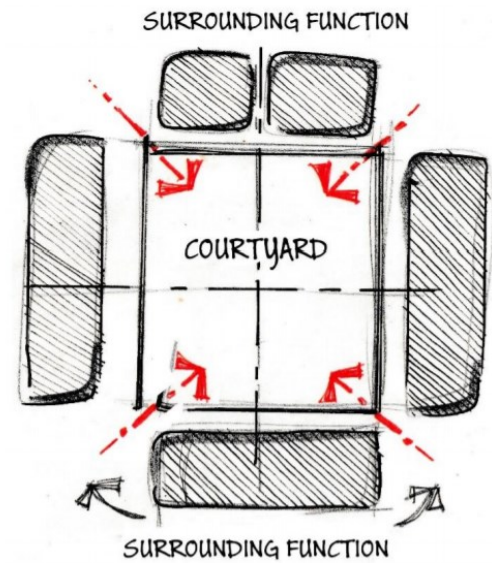

Figure 14. The courtyard as the design reference. [Source: the author]

Mashrabiya and Mandalon

To get to the courtyard, one has three main approaches, which allow different experiences and offer various views for each. The architect broke the linearity of the main entrance and carried it on a majestic arch to receive the visitor in a ceremonial atmosphere. Space is almost covered with vines, bushes, greenery, and trees dominated by several perfectly designed Mashrabiyas, two-level windows, and a Mandalon (an indoor porch that looks out on the court, covered with wooden twin arch as shown below) (figure 15).

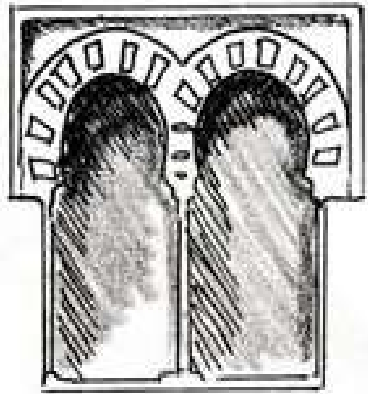

Figure 15. The Mandalon. [Source: the author]

At one of the corners, there is a wooden pergola with relaxing cushioned seats underneath, creating a shaded sitting space. The shadow and the sunlight that penetrates its gaps create a pleasant pattern on the floors and walls around. Also, walking on the traditional ornamented tiles just around the central fountain with flowerpots standing up all around assures the undeniable influence of Al-Andalus architecture on Zuaiter's design (figure 16).

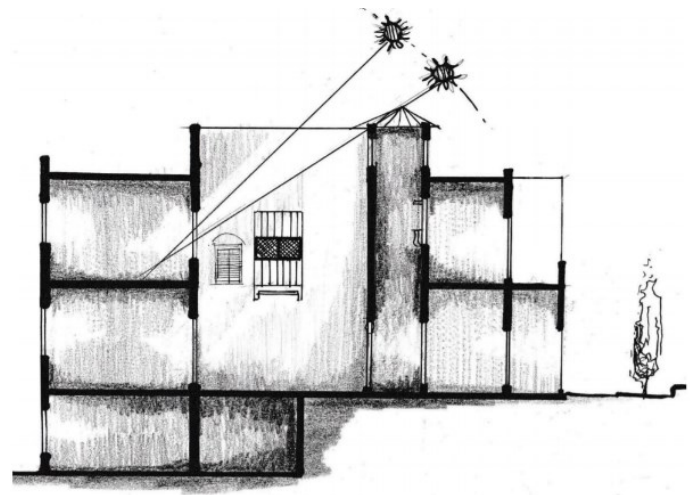

Figure 16. The infiltration of natural light through the courtyard and other openings (light and shadow relationship) [Source: the author]

Regular Courtyard

Zuaiter commented that although history shows that most of the courtyards were regular in shape, mostly rectangular, looking at this courtyard's initial plan, you will see an irregular shape. At first, Zuaiter started with this courtyard as a complete rectangle, and then made additions, subtractions, and inclinations until he got to this final shape. Despite this, Zuaiter has kept the main features of the original rectangle shape indirectly; he has emphasized on the main rectangular shape using a central rectangular fountain in the middle, and a pergola above the sitting area as shown in Figure 17. By so doing, Zuaiter has succeeded in maintaining the traditional appearance of the courtyard yet responding to space's needs and 
requirements. Therefore, he was able to control the main organizational axes of the court as well as a mix between formal and informal values of tradition.

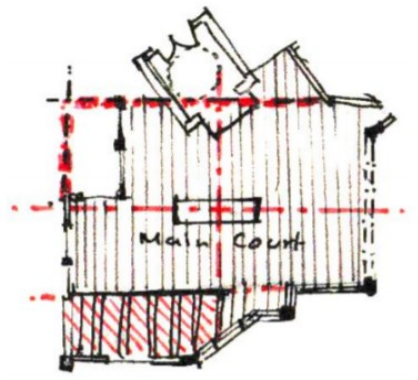

Figure 17. A sketch shows how Zuaiter succeeded in maintaining the main features of the rectangular courtyard shape. [Source: the author]

Going out of the courtyard, and moving towards the copper stairs leads you to the first floor, which is the private zone of the house (bedrooms), in a way that separates it from the other zones. An interesting point related to one of the bedrooms is the khalwa (the treated room, or relaxing place) where one could relax and be isolated in a very calm space. A Mashrabiya overlooks the central court, creating an enchanting mood by filtering the sunlight through the filigree patterns all around the room furniture and cooling the air inside. This concept has a religious basis as it reminds us of the place where one needs to feel pure, pray, and contemplate comfortably (figure 18 and 19).

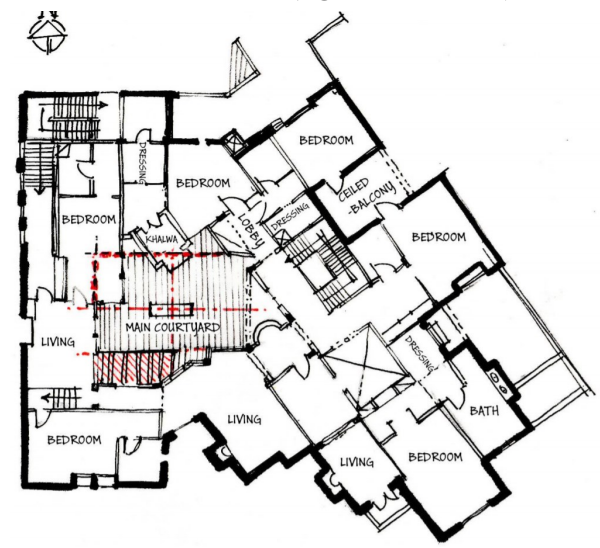

Figure 18. A sketch of Tabba'a house first-floor plan [Source: reproduced by the author]

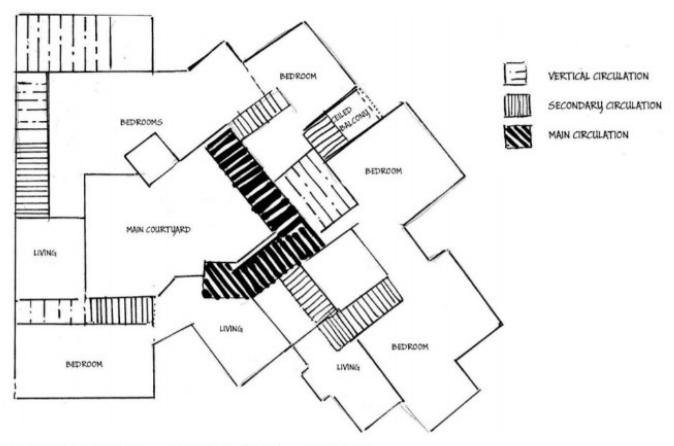

Figure 19. A sketch of the circulation system of the first floor [Source: reproduced by the author]

\section{Urban Space evolution}

Furthermore, Zuaiter added that he tries in his designs to revive the traditional urban spaces that have been imprinted in his memory from old Arab cities and neighborhoods he lived in or visited. What he found attractive in these urban spaces is the fact that they evolved to form the final shape they have today. Therefore, he tried to incorporate these urban spaces into his designs in a way that no one would feel that this house has been built at once, but it took its time to evolve and to be formed.

\section{Elevations: Richness is Indoor}

Regarding The elevations, Zuaiter applied the traditional concept of "richness is indoors," by making the part of the house that is exposed to the public to look as simple as possible while showing the rich details inside, such as Mashrabiya, Mandalon, wooden louvered windows, etc. In addition, Zuaiter used different types of materials, such as white stone, wood, cement blocks, and glass. Doing so shows successful integrity by mixing traditional and modern materials beside each other (figure 20-27).

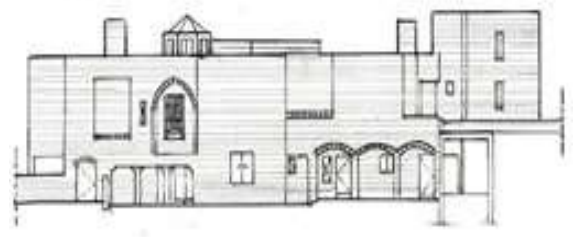

Figure 20. East elevation. [Source: reproduced by the author]

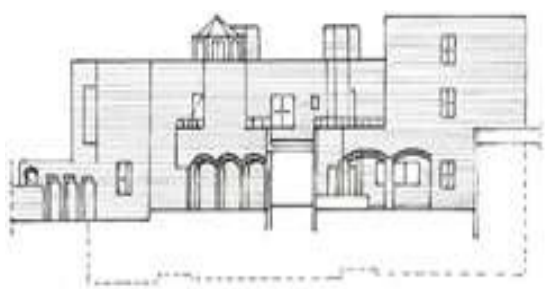

Figure 21. North elevation. [Source: reproduced by the author]

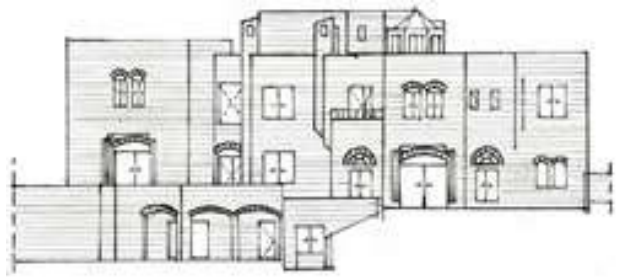

Figure 22. South elevation. [Source: reproduced by the author]

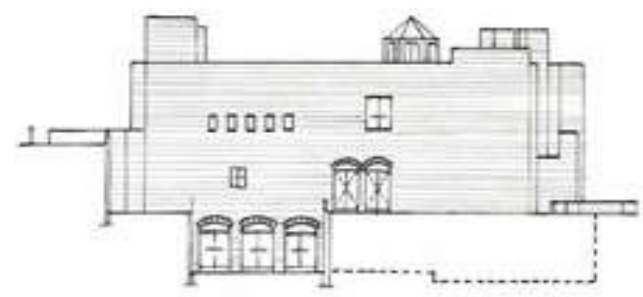

Figure 23. West elevation [Source: reproduced by the author] 
To sum up, by staying in such a place for a while and comprehending the spiritual experience it provides, one could recognize and appreciate the special touch this type of architecture adds.
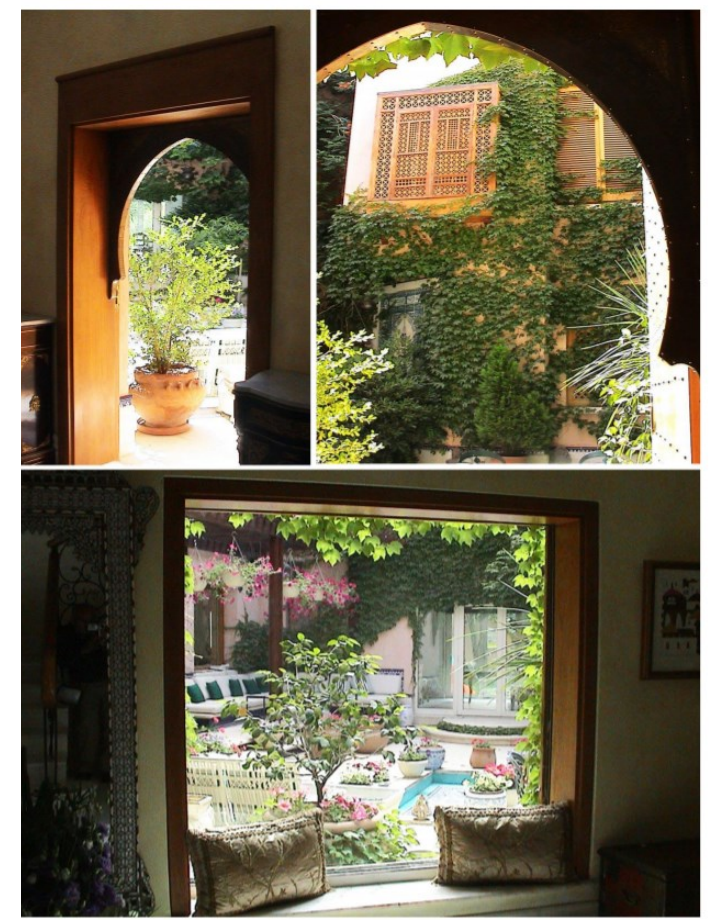

Figure 24. The court entrance door (Top) and a window overlooking the courtyard (Bottom) [source: the author]

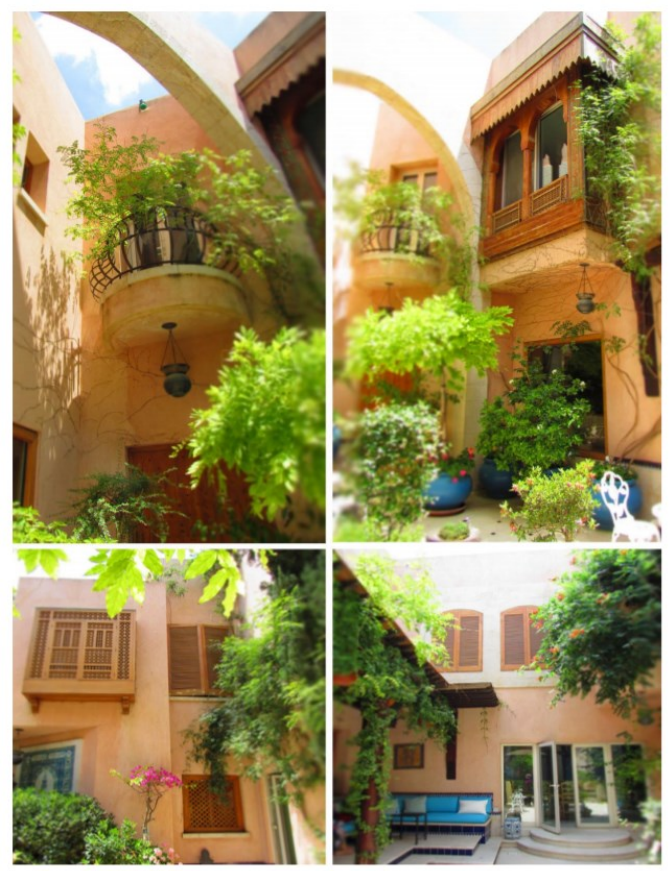

Figure 25. The courtyard entrance arch (top left); the Mandalon (top right); the Mashrabiya (bottom left); and the wooden louvered windows (bottom right). [Source: the author]
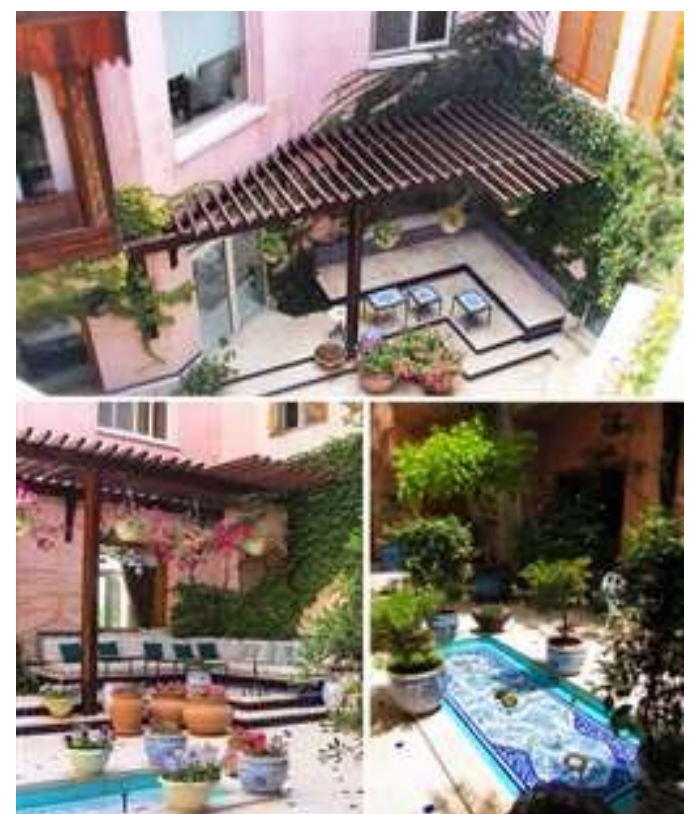

Figure 26. A top view of the courtyard pergola (Top; photo by Arch. Zuiater); the courtyard relaxing cushioned seats (Bottom left; photo by Arch. Zuiater); and the fountain (Bottom right photo by the researcher.
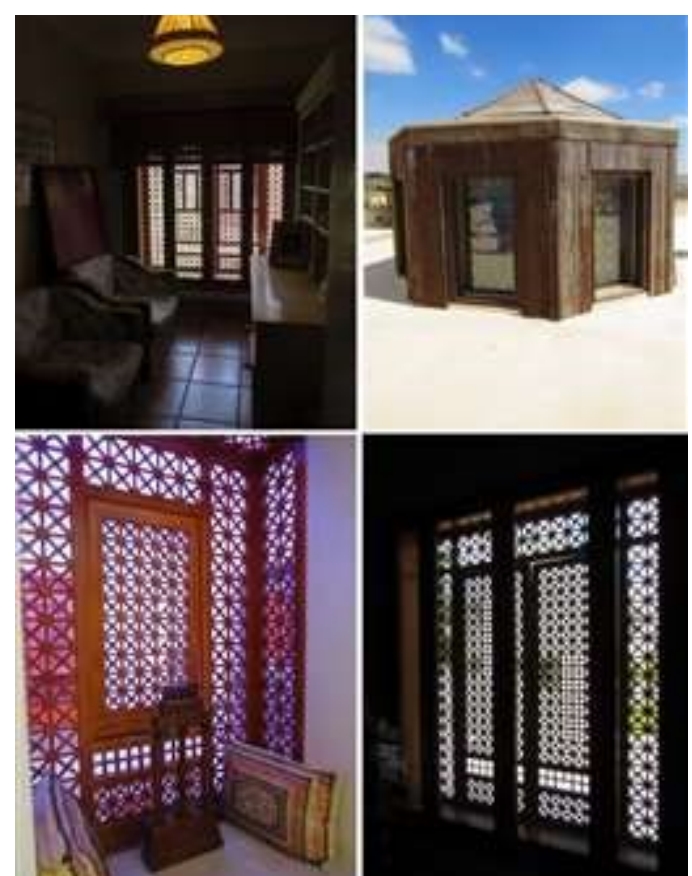

Figure 27. The khalwa (top left), the domed reception hall from outside (top right), and the Mashrabiya from the inside (bottom). [Source: the author]

\section{CONCLUSION}

The struggle between modernity and tradition in the Arab-Islamic world could be wisely described as a potent stimulator for reviving Islamic and traditional meanings and values in contemporary architecture, in addition to its role in maintaining the uniqueness and singularity of each context. The case study of Tabba's house has shown practically how "design" could serve as both methods through which unique forms are cre- 
ated, and as a production of distinguished architecture in itself that holds a distinct identity and could be applied, employed and built upon somewhere else.

Speaking of "distinguished architecture," an important point worth mentioning in this regard is the term Islamic architecture, which is not a style as one thing, but rather a description. It contains a diversity of expressions and tools through which underlying values and principles could be activated. It indicates its respect to the cultural differences and perception of it, and that is what Zuaiter has succeeded in achieving in his residential building Tabba'a house. The choice of a residential building in this study has proved how residential architecture acts as the community's cultural mirror and its people's reflection. Indeed, it is the most related type of architecture to humans, their culture, and beliefs. From an Islamic viewpoint, a house could be described as the microcosm of Islamic culture since it has been guided by the Islamic principles and values such as respecting human scale, modesty, clarity, symbolism, unity, privacy, etc. Besides, Islamic architecture has achieved fantastic success by taking into consideration both sides-aesthetic and functional-without ignoring one side on account of the other. To identify the Islamic cultural values that could be revived in contemporary Arab architecture, according to this study, see table 1 .

Table 1. some of the Islamic cultural values that could be revived in contemporary Arab architecture according to this study

\begin{tabular}{ll}
\hline & Design Elements \\
\hline some of the & Modesty \\
Islamic cultural & Privacy \\
values that & Adaptability \\
could be revived & Equity \\
in contempo- & Respecting the human \\
rary Arab archi- & Respecting the environment \\
tecture accord- & Responsiveness to the site's needs \\
ing to this study & Innovation \\
\hline
\end{tabular}

According to Zuaiter, Arab-Islamic traditional architecture could be defined as sensible responsive architecture that reacts simply to the social and environmental needs without y complications. To sum up Zuaiter's common design elements and concepts found in his analyzed case; Table 2. provides a helpful summary.

Table 2. Zuaiter's common design elements to maintain a regional architectural identity

\begin{tabular}{ll}
\hline & Design Elements \\
\hline Zuaiter's com- & - internal courtyard \\
mon design ele- & - Humble entrance door \\
ments to main- & - Richness is indoors \\
tain a regional & - Non-axial entrance \\
architectural & - The use of entrance court \\
identity & - human scale elements \\
& - The concept of an Islamic garden \\
& - Mashrabiya \\
& - Colored glass \\
& Dome and Lanterns \\
& -Triple volume entrance hall \\
& - The use of a pergola
\end{tabular}

\section{ELEVATION TREATMENTS}

In a way to provide a complete manifestation of a good combination of the old and new, elevation treatments must be considered along with the house plans. Zuaiter's design elements applied on the elevations offer a continuation of what the first plan draft has meant to provide, that is, stressing Islamic and cultural values in a modern, stylish way. The table 3 shows the elements found on Tabba'a house elevations.

Table 3. Elevation treatment

\begin{tabular}{ll}
\hline & Elements \\
\hline Elevation & - Arches \\
Treat- & - Mashrabiya \\
ments & - Two-meters high windows \\
& - Human scale elements \\
& - Colored glassed windows \\
& - Mandalon \\
& - Arcade \\
& - Gradualism in texture, color, and size \\
& - Humble doors \\
& - Arched doors and windows \\
& - Islamic horseshoe arches \\
\hline
\end{tabular}

\section{HOW MODERNITY WAS INVOLVED AND INTEGRATED WITH \\ ZUAITER'S CASE}

One could notice Zuaiter's use of modernity in several ways: Design tools, construction technologies, structural systems, the new materials, etc. Although new techniques allow discovering new materials and revealing their abilities, Zuaiter stresses on the importance of dealing with these contemporary tools as means and instruments, not as aims or targets by themselves. Doing so gives better end products. Indeed, this could be described as adaptability with whatever new challenges and struggles appear around. Therefore, the meaning of integration is to incorporate old and new to produce a compatible result that suits its context and people. For example, Zuaiter uses modern design strategies such as open plans to suit the contemporary lifestyle in some cases. From the previously mentioned points, one could integrate modernity and tradition without compromising or sacrificing identity.

In a way to unfold what Islamic values have been delivered through each design element applied, Table 4 concludes the study findings.

The results apply to both the house plans and elevations, incorporating the Islamic values with the modern ones and articulating a personal identity that responds to the context, its people, culture, and heritage. The inductive approach used as the research methodology is mostly helpful regarding making the invisible visible [16]. Through the tables concluded, architects and designers could develop an initial design guide that helps in define a unique cultural, architectural identity in the region, as well as bridging the gap between modernity and tradition in contemporary Arab architecture. 
Table 4. what Islamic value has been delivered through each design feature

\begin{tabular}{|c|c|}
\hline Design Element & Islamic value \\
\hline - internal courtyard & $\begin{array}{l}\text { - Privacy, Respecting the envi- } \\
\text { ronment }\end{array}$ \\
\hline Humble entrance door & - Modesty, Social equity \\
\hline Richness is indoors & - Social equity, Modesty \\
\hline Non-axial entrance & - Privacy \\
\hline $\begin{array}{l}\text { The use of entrance } \\
\text { court }\end{array}$ & $\begin{array}{l}\text { - Privacy, Respecting the envi- } \\
\text { ronment }\end{array}$ \\
\hline Human scale elements & $\begin{array}{l}\text { - Respecting the human, Modes- } \\
\text { ty, adaptability }\end{array}$ \\
\hline $\begin{array}{l}\text { The concept of an Islam- } \\
\text { ic garden }\end{array}$ & $\begin{array}{l}\text { - Respecting the environment } \\
\text { and responsive to the site's } \\
\text { needs }\end{array}$ \\
\hline Mashrabiya & $\begin{array}{l}\text { - Privacy, Respecting the envi- } \\
\text { ronment, innovation }\end{array}$ \\
\hline Colored glass & - Privacy, Aesthetic purposes \\
\hline \multicolumn{2}{|l|}{ Dome and windows } \\
\hline $\begin{array}{l}\text { Lanterns and the use of } \\
\text { a pergola }\end{array}$ & $\begin{array}{l}\text { - Modesty, Respecting Environ- } \\
\text { ment }\end{array}$ \\
\hline Mandalon & $\begin{array}{l}\text { - Privacy, Respecting the Human } \\
\text { and the environment }\end{array}$ \\
\hline $\begin{array}{l}\text { The use of Arches and } \\
\text { Arcade }\end{array}$ & $\begin{array}{l}\text { - Esthetic purpose, Respecting } \\
\text { the Environment, Innovation }\end{array}$ \\
\hline $\begin{array}{l}\text { Gradualism in texture, } \\
\text { color, and size }\end{array}$ & $\begin{array}{l}\text { - Adaptability, Respecting the } \\
\text { human, Responsive to the site's } \\
\text { needs }\end{array}$ \\
\hline
\end{tabular}

\section{ACKNOWLEDGEMENT}

The author is very grateful to Applied Science Private University ASU (Amman, Jordan) for supporting this work through the scholarship granted to the author.

\section{REFERENCES}

[1] C. Correa, "Quest for Identity," in Proceedings of the Seminar: Exploring Architecture in Islamic Cultures: Architecture and Identity, 1983, pp. 10 -13 .

[2] W. Al-Sayyed, "Contemporary Arab Architecture: Space, Form, and Function," Lonaard Journal, vol. 2, no. 7, pp. 49-75, 2011.

[3] M. S. A. Al-Ataabi and A. A. Jalowb, "The spiritual impact of the original decorative product in contemporary Islamic Arab architecture," The iraqi journal of architecture and planning, vol. 14, no. 2, pp. 247-268, 2018.

[4] R. Al-Abbassi, "The Impact of Local Culture on Shaping an Architectural Identity," University of Jordan, 2003.
[5] M. K. Ali, "The use of precedents in contemporary Arab architecture: Case studies; Rasem Badran and Henning Larsen," MASSMIT: Massachusetts Institute of Technology, 1989.

[6] A. Ajaj and F. Pugnaloni, "Re-thinking traditional arab architecture: a traditional approach to contemporary living," International Journal of Engineering and Technology, vol. 6, no. 4, pp. 286-289, 2014.

[7] K. Asfour, "Polemics in Arab architecture: theory versus practice," ArchNet-IJAR, International Journal of Architectural Research, vol. 1, no. 1, pp. 53-69, 2007.

[8] M. Abedi and H. Soltanzadeh, "The Interaction between Tradition and Modernity in Contemporary Architecture of Persian Gulf States: Case Study of United Arab Emirates," International Journal of Research in Humanities and Social Studies, vol. 1, no. 1, pp. 24-34, 2014.

[9] W. Alsayyed, "Tradition and contemporary, versus theory and practice," University of Jordan, 1995.

[10] R. Anderson and J. Al-Bader, "Recent Kuwaiti architecture: regionalism vs. globalization," Journal of architectural and planning research, vol. 23, no. 2, pp. 134-146, 2006.

[11] M. Matrouk and J. Goussous, "Recipient Cognition and House Identity in Jordanian Architecture," Anthropologist, vol. 13, no. 4, pp. 271 $-281,2011$.

[12] A. M. El-Shorbagy, "Traditional Islamic-Arab house: Vocabulary and syntax," International Journal of Civil \& Environmental Engineering, vol. 10, no. 4, pp. 15-20, 2010.

[13] S. Akkach, Cosmology and architecture in premodern Islam: an architectural reading of mystical ideas. New York: SUNY Press, 2012.

[14] E. Clark, The Art of the Islamic Garden. Wiltshire: Crowood Press, 2004.

[15] N. Asif, N. Utaberta, M. O. Mydin, and M. M. Yunos, "Redefining Islamic garden: Comparative analysis of approaches, ideas and design framework," Jurnal Teknologi, vol. 75, no. 9, pp. 77-81, 2015.

[16] O. M. Jarrar, "Cultural Influences in Jordanian Architectural Practices: Post 1990," University of Calgary, 2013. 